\title{
Evaluation of Accessibility to Public Services in the City of Aqaba Using Geographic Information Systems
}

\author{
AbedAlhameed AlFanatseh ${ }^{1} \&$ Shahed Saqallah ${ }^{2}$ \\ ${ }^{1}$ Department of Geography, Al-Hussein Bin Talal University, Ma'an, Jordan \\ ${ }^{2}$ The Ministry of Education, Ma'an, Jordan \\ Correspondence: AbedAlhameed AlFanatseh, Al-Hussein Bin Talal University, Department of Geography, Ma'an, \\ Jordan, Jordan
}

Received: August 19, 2021

Accepted: November 15, 2021

Online Published: November 29, 2021

doi: $10.5539 /$ jgg.v13n2p17

URL: https://doi.org/10.5539/jgg.v13n2p17

\begin{abstract}
In this study, we identify methods of measuring accessibility to public services in the city of Aqaba. Accessibility is an indicator of the efficiency of their spatial distribution in relation to residential neighborhoods in the city. Administrative, commercial, educational, health and entertainment services were selected for a case study because they are the most important services. We used spatial analysis tools in Arc Map within the geographic information systems (GIS) environment to measure direct distances between neighborhood centres and public services and to determine the number of services within specific ranges $(1,000 \mathrm{~m}, 500 \mathrm{~m}, 200 \mathrm{~m})$, using the three most common methods of measuring accessibility: the distance to the nearest service, the number of services within a certain distance or time, and the average distance for all services. The results of this research indicate that educational services have the highest degree of accessibility, followed by slight differences among recreational, administrative, and commercial services. Health services lag further behind.
\end{abstract}

Keywords: Public services, accessibility, geographic information systems, Aqaba

\section{Introduction}

Good public service is a cornerstone of human development, and its input is essential. If quality-of-service dimensions are multiple and varied, then ease of obtaining services is at the forefront of these dimensions. Fast and easy accessibility to public services is necessary for ease of obtaining services, which is mainly related to the good geographical distribution of public services among administrative units and consistent with population size and the primary road network (Shalaby, 2005).

The organization of public services in the city is both an objective and a means: making services more accessible to the population, serving the various purposes of society, and achieving the desired standard of living. The general idea of the distribution of public services on the surface of the city is to establish a hierarchy of necessary services in terms of size and the corresponding population. Some services require a minimum population to justify the cost of establishing them, such as educational services, health services, and commercial services. Other services can be established according to the number of residents who want them, such as public parks. What determines whether they are needed is what is decided as a minimum per capita. Therefore, a hierarchical scale for each of the main services (educational, health, commercial, and administrative) is a starting point. Each service is based on the residential group that it serves because each service has a special scope of influence. The rest of the services are added according to the population of each group, such as educational services, health services, and commercial services (Abdullah, 1990).

The movement patterns of individuals are affected by two levels: the spatial structure of residential neighborhoods and the urban spatial structure (the city), of which the neighborhood structure is a part. The variations in the pattern of activities and their spatial distribution at the two levels result in variations in the pattern and quantity of the movement of individuals. This structure is often measured using the indicators of population density and the proportion of job opportunities available relative to the number of neighborhoods. Handy, (1997) noted that the previous two indicators are not sufficient to define the relationship between the two structures (neighborhood and city) because the measure of accessibility is another important tool for determining the relationship of mutual 
influence. Gutierrez, (1980) posited that accessibility is an important characteristic in urban areas. Because accessibility is the most realistic measure of the degree of integration between land use and the urban transport system, it can be used as one of the evaluation criteria in studies analyzing the efficiency of the transport system and in the field of formulating policies for urban planning. Karst, (2004) also believed that transport planning plays a fundamental role and can be used to measure the social justice associated with the spatial distribution of services in the population centres of various social and economic levels (Karst 2004).

The different purposes for studying accessibility and the different local conditions of the urban area make choosing the most appropriate method for measuring it of fundamental importance. Karst, (2004) defined four criteria that he derived from multiple studies. The first is that the method must be sensitive to changes in the transportation system, that is, to assess the extent of ease or difficulty that enables individuals to traverse the distance from the origin area to the target area using a method-specific transport measured by distance traveled, time, or effort exerted. The second criterion is that the method be sensitive to changes in the pattern of land use, that is, to measure the quantity, quality, and spatial distribution of available opportunities (activities and services) and the demand for those opportunities, considering the impact of the competition among those opportunities. The third criterion is that the method be sensitive to the constraints of the times in which the opportunities are available; and the fourth is that it must consider the requirements, capabilities, and opportunities of individuals. These criteria cannot be considered absolute but are rather a general line of study on accessibility.

The current study is designed to achieve the following objectives:

1. Analyze and evaluate the ease of access to public services in the city of Aqaba using different statistical and cartographic methods within the environment of geographic information systems (GIS).

2. Assess the status quo for the distribution of public services by determining which neighborhoods in the city are not covered by public services (not served) within a certain distance.

3. Identify the capabilities inherent in GIS technology in applying spatial analysis methodology to measure the accessibility of public services in the city of Aqaba using spatial analysis tools.

\section{Literature Review}

Many studies have examined the optimal situation for the distribution of services within cities. Many studies have addressed ease of access to public services in general or a specific service to assess the current status of services and their accessibility. The most important of these studies follow.

Albacete et al. (2017) published a study entitled "Measuring the Accessibility of Public Transport: A Critical Comparison Between Methods in Helsinki." The study compared two of the scales used to assess the accessibility of public transportation in the city of Helsinki. The study also focused on determining the most important factors affecting ease of access to public transportation. The study relied on the comparative approach in addition to using the structural access layer for public transportation as an indicator of ease of access, and walking was used as an indicator of ease of access. This study relied mainly on the application of these two methods to the study area to give planners and decision-makers a simple measure to assess the ease of access to public transportation.

A study by Polo et al. (2015) was entitled "Location-Allocation and Accessibility Models for Improving the Spatial Planning of Public Health Services." The study searched for ways to improve the spatial planning of public health services, integrating accessibility and location-allocation models. Available in GIS, the model was applied by the authors the minimum movement resistance model, and the results of the accessibility model showed that the northern, central, and southern regions are not covered by the Vaccination program. The results of the maximum coverage model and the minimum movement resistance model showed that to improve spatial accessibility, vaccination sites needed to be re-signed.

Park (2012) study is entitled "Measuring Public Library Accessibility: A Case Study Using GIS." For accuracy, the researcher relied on descriptive and statistical approaches to measure distances based on the road network. The results of the study indicate that distance is a decisive factor in library users' ease of access and that distance affected numerous users who lived within the areas defined by Thiessen polygons. People recommended assessing the needs of user groups and developing library programs and services to meet those needs.

A study by Neutens et al. (2010), "Evaluating the Temporal Organization of Public Service Provision Using SpaceTime Accessibility Analysis," used temporal and spatial accessibility analysis to explore the impact of changes in working hours on social service provision. To this end, they implemented an accessibility model and used it in a case study of the provision of public services in the urban area of Ghent, Belgium. Among the findings of the study 
is that access to public services changes significantly from hour to hour and day to day, but their results also show that individuals with personal and family characteristics are affected differently by changes in the time system of public service facilities.

Nicholls' (2010) study, "Measuring the Accessibility and Equity of Public Parks: A Case Study Using GIS," measured the levels of accessibility of public parks in Bryan, Texas, using GIS. Nicholls established a geographical database that provides data to recreational institutions to enhance their planning and the management of their facilities, to identify the areas that lack recreational services, to identify appropriate sites for the establishment of new recreational services, to achieve justice in the spatial distribution of recreational services, and to achieve the desired goals. The study adopted the spatial analysis and diagnostic approaches and used several quantitative methods. One of the findings of the study is that GIS applications can enable entertainment agencies and institutions to work more effectively in planning recreational services, and they provide better levels of service.

A study by Tindall (2005) entitled "Local Transportation Plan Accessibility Study" assessed ease of access by creating a model for a local transportation plan. The researcher relied on fragmented information and integrated data to obtain indicators of access to public services. This included the model developed by the researcher to obtain information such as the road and public transportation network and general information about the city and the existing neighborhoods. The study showed that despite the dispersed nature of the population in the study area, public services are available in locations that are easily accessible using public transportation.

A study by Chapin et al. (2002) entitled "Urban Land Use Planning" developed a model to measure the ease of urban access to reflect the integration and compatibility of patterns of urban development of lands, and transportation infrastructure. The authors relied on five main types of accessibility scales to evaluate several issues that developed and were studied with this model. The scales were discrete spatial information, or graph theory; the scale of cumulative opportunities; the scale of attractiveness; the scale of sharing several features with the scale of gravity; and a scale that contained separate information, such as hourly time. The study showed that the measures of cumulative opportunity and the scale of attractiveness were the most compatible measures of accessibility with the study area, and they were evaluated using data from the study area (Dallas/Fort Worth region).

Al-Sahili, and Aboul-Ela's (1992) study, "Accessibility of Public Services as an Indicator of Transportation System Sustainability: The Case of Irbid, Jordan," assesses the connectivity of public service sites in the city of Irbid. Ibrid is divided into 17 regions, and schools, health facilities, post offices, mosques, gas stations, public security centres, and banks were distributed throughout each region. Each service represents the maximum distance that is reasonable to reach a service location, so the coverage distance was used to indicate the fully or partially serviced areas and unserved areas. The results of the study showed that the city centre is fully served by many public services, but there are other partially serviced and unserved areas. Where services are concentrated in the outskirts of the city, as was determined by the study, the ability to access public services was good and was commensurate with the serviced population.

\section{Study Area}

The city of Aqaba is located in the Hashemite Kingdom of Jordan southwest of the capital, Amman. Aqaba is about $350 \mathrm{~km}$ and extends between latitudes (o29 3443 and o29 29 41), and extends between longitude (o34 58 25 and 03503 33), as shown in Fig. (1) The city of Aqaba (the centre of the Aqaba governorate) occupies an area estimated to be 19,571 dunums and has a population of 148,398 people (Department of Statistics, 2015). The city of Aqaba is divided administratively into 42 residential neighborhoods. The population density of Aqaba city is 7.6 inhabitants per dunum. The city centre, which includes most of the commercial and administrative activities, is located within the old quarters of the city. 


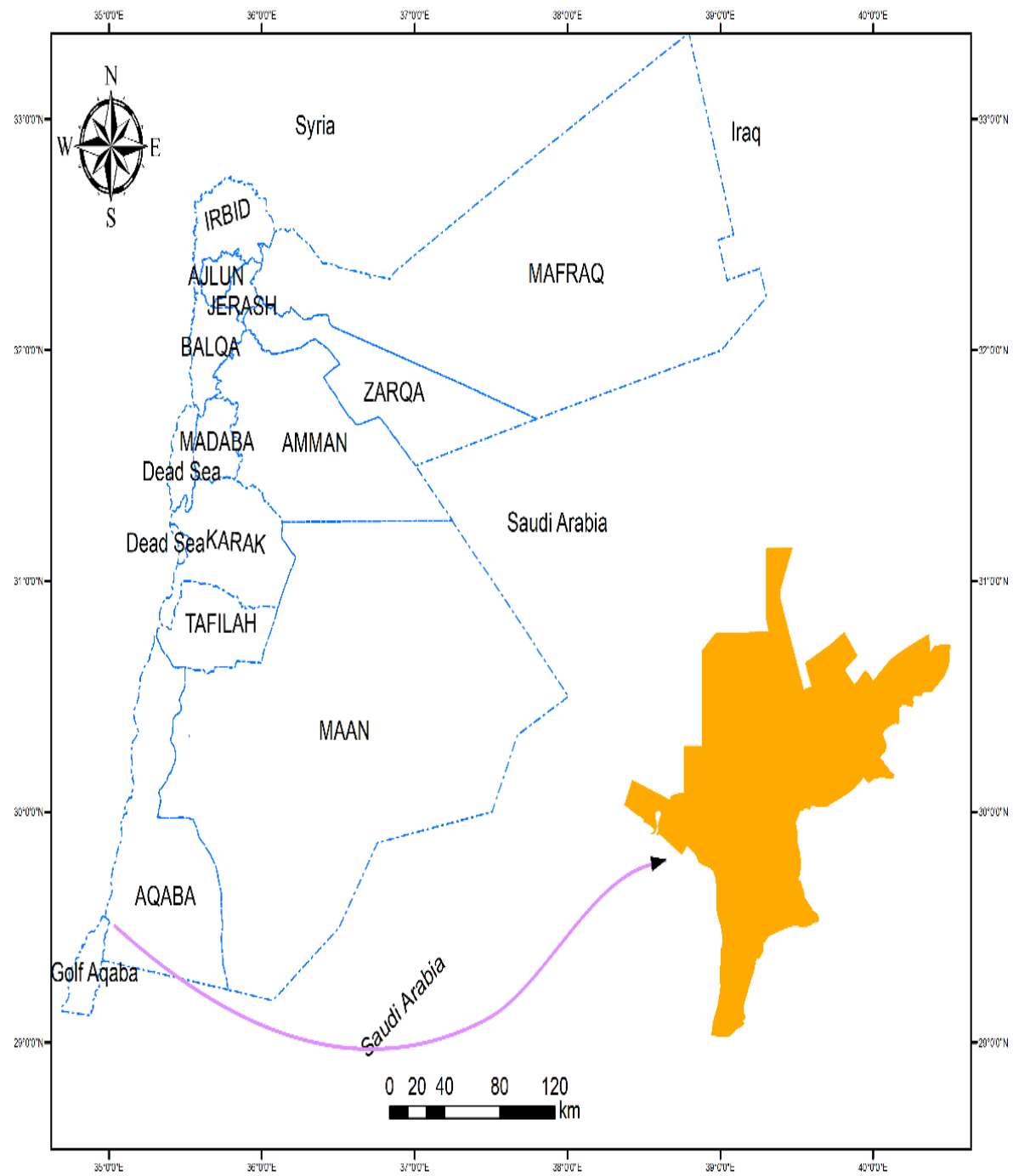

Figure 1. The Study Area

The city of Aqaba is an important model for Jordanian cities with regard to the development it has witnessed in all fields, especially in the field of urban development. The city of Aqaba has developed and expanded: its urban area expanded, and its neighborhoods multiplied. The result of this expansion is increased pressure on urban areas at rates that exceed the city's ability to provide various services and jobs in sufficient quantity and quality. This has resulted in many problems related to deficiencies in most types of services. In addition, city leaders did not consider planning foundations or measures of accessibility for services, which resulted in chaos in the use of land and the inability of some neighborhoods in the city to provide services to the population at the appropriate level. The prevailing services at the neighborhood level and the level of the city as a whole have affected the dispersion of services, their spacing, and the scarcity of supplies to serve the city's residents.

In addition, the city's population increased; the population growth rate in Aqaba is one of the highest in the Kingdom. The annual growth rate from 2004 to 2015 reached 4.1\% (Department of Statistics, 2004-2015), which led to the need to establish many services in Aqaba's various residential neighborhoods, including schools, health centres, mosques, markets, and public places. Because of the changing environment of the population, these new services necessitated the re-examination of public service sites because they may not be as efficient, effective, and accessible as they were in previous years.

The importance of this study also lies in the necessity to study the issue of ease of access to public services and linking them with transportation in the city of Aqaba because Aqaba is considered a special economic zone. In 
addition to providing the necessary information about the efficiency of the current distribution of public services, I will evaluate ease of access to services to establish more service units in areas of shortage.

\section{Methodology}

To achieve the objectives of the study the descriptive and analytical approaches were used, which are based on studying the phenomenon as it is and then describing it accurately, expressively, and quantitatively. I studied the public services in the city of Aqaba in terms of their spatial distribution, spread, and ease of access to highlight their spatial characteristics. GIS have been applied to determine the scope of impact for each service, and I have tried to take advantage of the capabilities of GIS, depending on the ArcGIS program to manage data (spatial and descriptive) after entering it and outputting it in the form of maps of various topics. The purpose of using the program was to build an information base and link metadata with spatial data to design and produce the necessary maps, depending on the relationship between spatial data (map layers) on the one hand and the relationship of this data to the metadata associated with it within the program's system on the other.

\subsection{Data Sources}

The data used in this research were collected from the Aqaba Economic Zone Authority and the Department of Statistics. The research was based on a map of land use in the city of Aqaba, which was obtained from the Aqaba Economic Zone Authority 2020. In addition to the map of neighborhoods, I used maps of administrative boundaries and the road network of Aqaba for the year 2020, all of which were derived from the GIS Section of the Department of Statistics. The high-resolution, geometrically corrected satellite visuals $(1 \mathrm{~m})$ of the city of Aqaba for the year 2020 were based on the Ashplant program, and population data were obtained from the Department of Statistics, Population and Housing Census of Aqaba City 2007 and the Estimates for population and housing for the year 2020.

\subsection{Data Analysis and Processing Tools and Procedures}

The research is integrated with the technology of GIS and methods of geospatial analysis. I analyzed the study data and treated their variables, utilizing some geographical spatial and statistical analysis methods and following Apparicio, (2008).

Apparicio, (2008) identified five methods of measuring accessibility and used the most common and most accurate methods of selecting the starting and arriving centres and expressing distance, as will be mentioned later.

The first method is the distance to the nearest service, using the following mathematical formula:

$$
z_{i}^{a}=\frac{\sum_{b \epsilon i} w b\left(\min \left|\mathrm{d}_{b_{5}}\right|\right)}{\sum_{b \epsilon i} w b}
$$

where $Z_{\mathrm{i}}^{\mathrm{a}}$ is the average of the distance between the departure centre and the nearest service, $\mathrm{W}_{\mathrm{b}}$ is the total population of the originating area $b$ within the total urban area $I$, and $d_{b s}$ is the distance between starting area $b$ and service $\mathrm{s}$.

The second method is calculating the number of services within a certain distance (or time). In the following formula,

$$
z_{i}^{b}=\frac{\sum_{b \epsilon i} w b \sum_{j \epsilon s} s j}{\sum_{b \epsilon i} w b}
$$

$\mathrm{Z}_{\mathrm{i}}^{\mathrm{b}}$ is the average number of services within a specified distance from the starting centre, $\mathrm{W}_{\mathrm{b}}$ is the total population of the originating area $b$ within the total urban area $\mathrm{I}, \mathrm{S}$ is the total number of services, and $\mathrm{S}_{\mathrm{J}}$ is the number of services within a specified distance (time) from the starting centre equal to (1) when $n \leq d_{b s}$ and equal to (0) when $\mathrm{n}>\mathrm{d}_{\mathrm{bs}}$. 
The third method is calculating the average distance for all services. In the following formula,

$$
z_{i}^{c}=\frac{\sum_{b \in i} w b^{d} b s}{\sum_{b \in i} w b}
$$

$\mathrm{Z}_{\mathrm{i}}^{\mathrm{c}}$ is the average distance between the launch centre and all services, $\mathrm{W}_{\mathrm{b}}$ is the total population of the originating area $\mathrm{b}$ within the total urban area $\mathrm{I}$, and $\mathrm{d}_{\mathrm{bs}}$ is the distance between starting area $\mathrm{b}$ and service $\mathrm{s}$.

The fourth method is calculating the average distance for a certain number of services. In the following formula,

$$
z_{i}^{d}=\frac{\sum_{b \in i} w b \sum_{s} \frac{d b s}{n}}{\sum_{b \in i} w b}
$$

Zid is average distance between the centre of departure and $\mathrm{n}$ of the nearest services, $\mathrm{Wb}$ is the total population of the originating area $b$ within the total urban area $I, d b s$ is the distance between starting area $b$ and service $s$, and $n$ is the specified number of the nearest services.

The fifth method is the gravitational model. In the following formula,

$$
z_{i}^{e}=\frac{\sum_{b \in i} w b \sum_{s} w{ }^{d} \bar{b}_{s}^{a}}{\sum_{b \in i} w b}
$$

Zie is the average value of the underlying gravitational pull, $\mathrm{Wb}$ is the total population of the originating area $\mathrm{b}$ within the total urban area i, $\mathrm{S}$ is the total number of services in the study area, dbs is the distance between starting area $b$ and service $s, \alpha$ is the coefficient of friction (take the values 1,1.5,2), and Sws is a weight given to the service is based on its size (for example, the number of beds in a hospital).

There are several ways to represent staging areas (the origin). To assess the accessibility of services for residents of a given residential area, there are three ways to represent the locations of individuals (Hewko, 2002). The first method is the adoption of the engineering centre (centroid) for all residential neighborhoods. As shown in Fig. (1a), this method does not consider variations in residential densities or the nature of the spatial distribution of residents within the residential neighborhood.

The second method is to adopt the following formula:

$$
\left(x_{i}, y_{i}\right)=\left\{\frac{\sum_{b \in i} w b x b}{\sum_{b \in i} w b} \frac{\sum_{k \in i} w b x b}{\sum_{b E i} w_{b}}\right\}
$$

This formula will determine the coordinates of the centre of the residential neighborhood. The residential neighborhood is divided into homogeneous groups of residential densities and then given a weight that fits the population size of each spatial unit (it may be a housing unit, a residential block, or a group of residential blocks) in relation to the total size of the neighborhood's population. The result will be a residential centre which prefers the more populated areas. Population density does not match the geometric centre and is called the populationweighted mean centre, as shown in Fig. (2.b). The third method does not depend on a single centre for the residential area but deals with all centres of the approved spatial units. All distances from these centres to the services are measured, and then the average of these distances is calculated with weighting based on the population size of each approved spatial unit. These results appear in Figure (2c) 


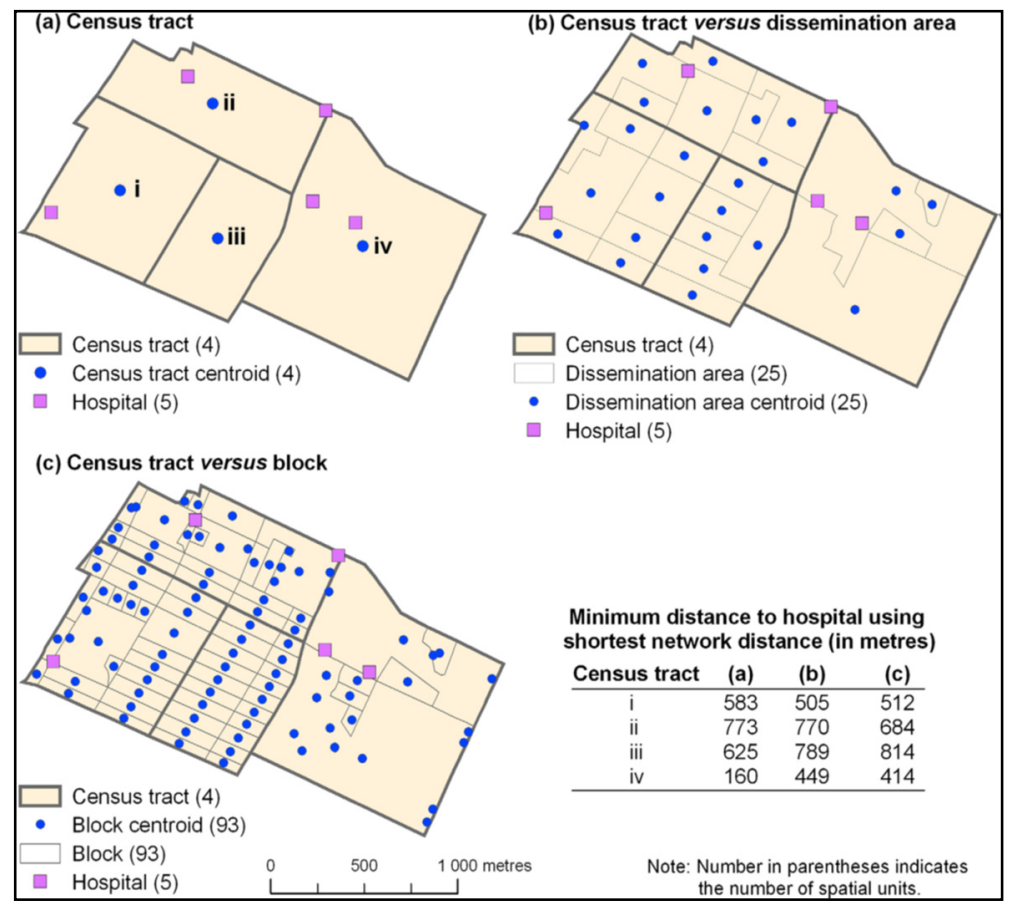

Figure 2. Methods of Representing the Spatial Units of Residential Neighborhoods

Source: Apparicio, 2008, p. 3

There are four ways to express distance, which can be seen in Figure (3). The first way is Euclidean distance, which represents the direct measurement between the centre of the starting area and the centre of the arrival area. The second method is Manhattan distance, which represents the distance along the two straight sides opposite the chord (direct distance). The third way is the distance to the shortest path on the road network (shortest network distance) between the centre of the starting area and the centre of the arrival area. The fourth way is the time for the shortest path on the road network (shortest network time) between the centre of the starting area and the centre of the arrival area.

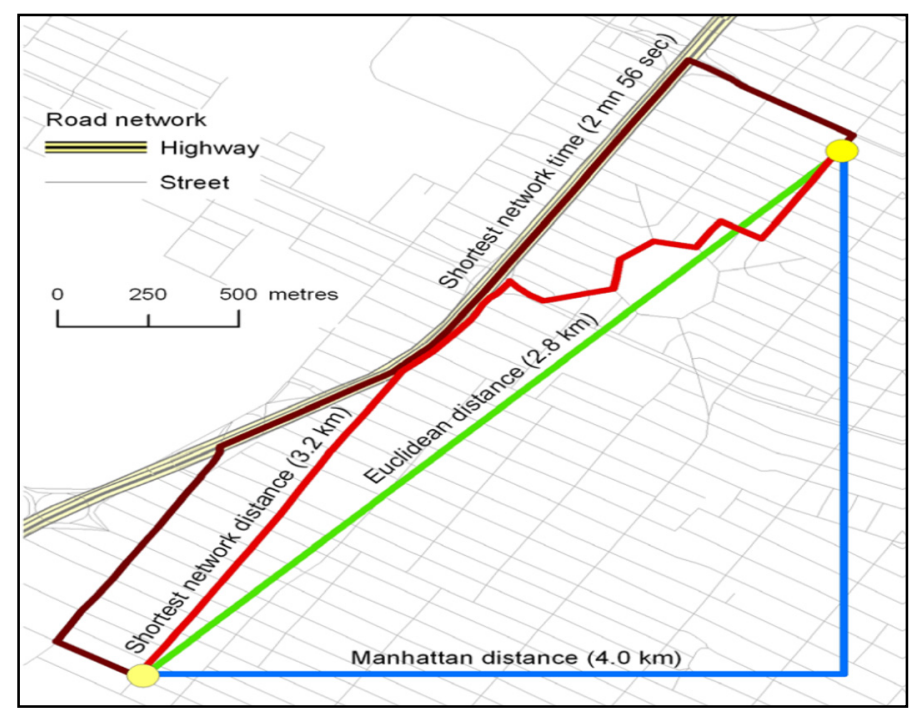

Figure 3. Methods for Expressing Distance. Source: Apparicio, 2008, p. 5 


\section{Discussion}

This section contains analysis of the results of the three measures of accessibility, first based on actual distances and then based on the distances weighted by the population size of each residential neighbourhood. The first measurement is of accessibility to public services in the city of Aqaba using GIS. I measured the distribution of public service sites and the locations of residential neighborhoods within the city as a primary factor for determining accessibility and regardless of the frequency of their use by people. The calculations of actual distances were weighted by the population size factor. The first distance measured was to the nearest service. Toolbox Analysis (Proximity-Near) identified the actual distance between the neighborhood centre and the closest location of the five services selected for measurement. The results are shown in Table (1) (distance method to the nearest service). This Table indicates the direct distance between the centre of each neighborhood and the nearest meter-measured service. See Fig. (4).

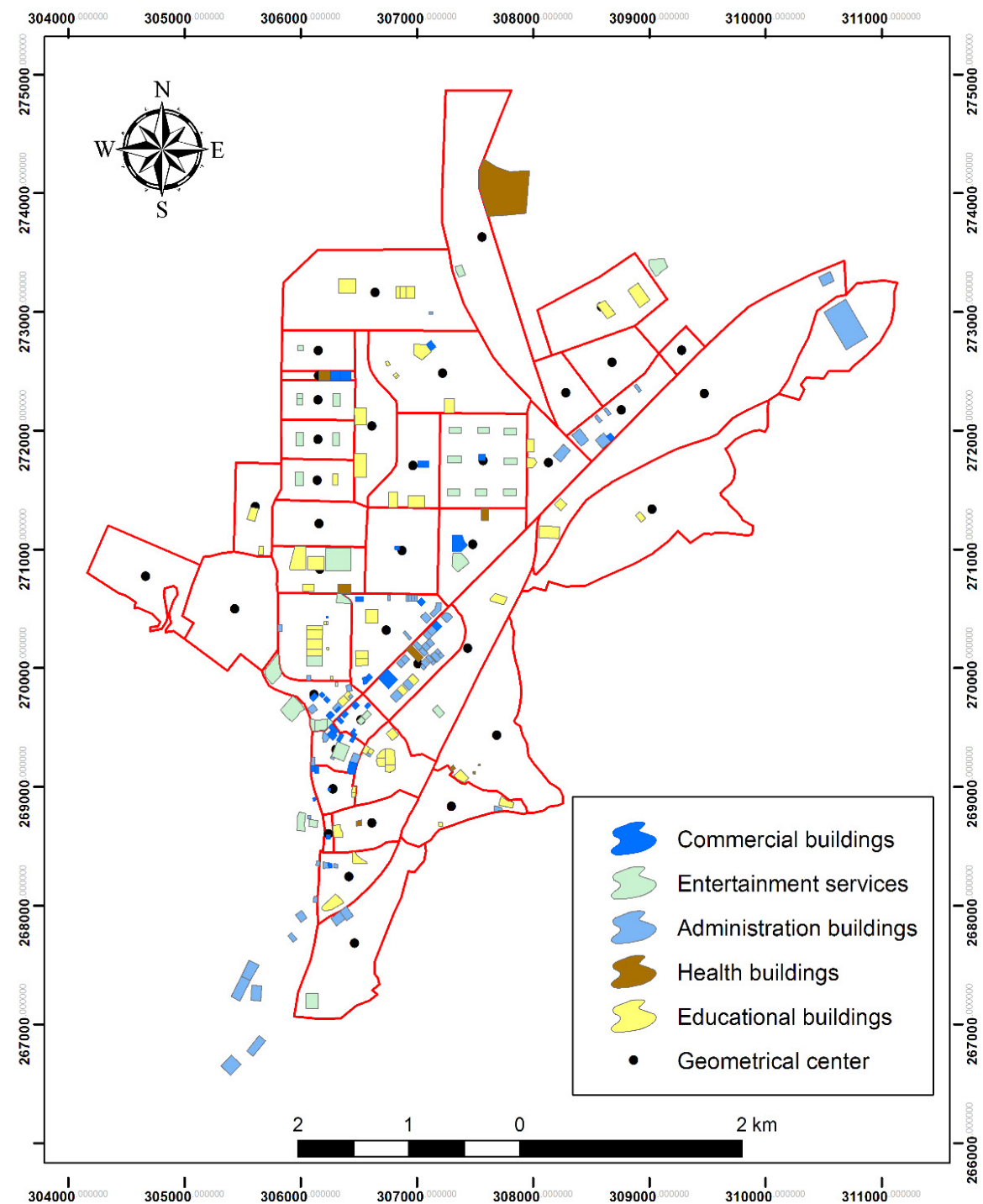

Figure 4. Measuring the Nearest Commercial Service.

Source: Preparation of researchers 
The second method measures the number of services within a certain distance, Using the tool Create Buffer, barriers in GIS mean the borders that surround one of the geographical phenomena on the map (point, line, polygon) with equal distances from those phenomena separating the map into two types of areas. One area is located within a specified distance called the Buffer Zone, which expresses a specific event; and the other is behind it. Barriers with radii of $200 \mathrm{~m}, 500 \mathrm{~m}$, or $1000 \mathrm{~m}$ were set up around the centres of each residential neighborhood, and the number of services within each barrier were counted as well as each service separately. The results, the number of services within a distance, are presented in Table (2). See Fig. (5).

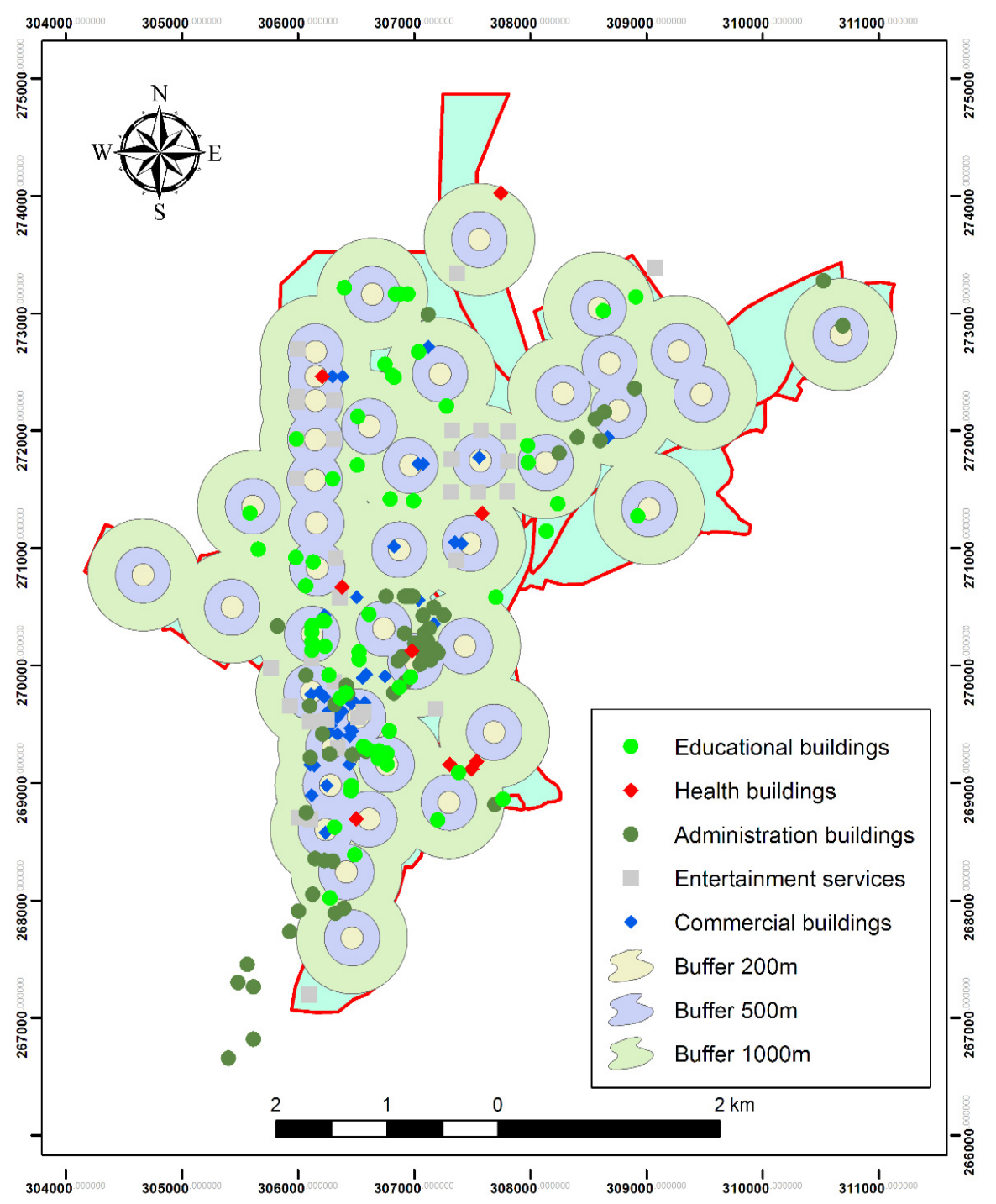

Figure 5. Calculating the Number of Recreational Services for each $200 \mathrm{~m}, 500 \mathrm{~m}$, and 1000m range

(as an example)

Source: Preparation of researchers.

The third method measures average distance for all services. Using the Toolbox Analysis Tool (Proximity-Point Distance), we calculated the sum of the distances between the Mahalla centre and all the sites for each service. We then averaged these distances by dividing by the number of services. The results are presented in Table (3) (average distance method for all services). See Fig (6). 


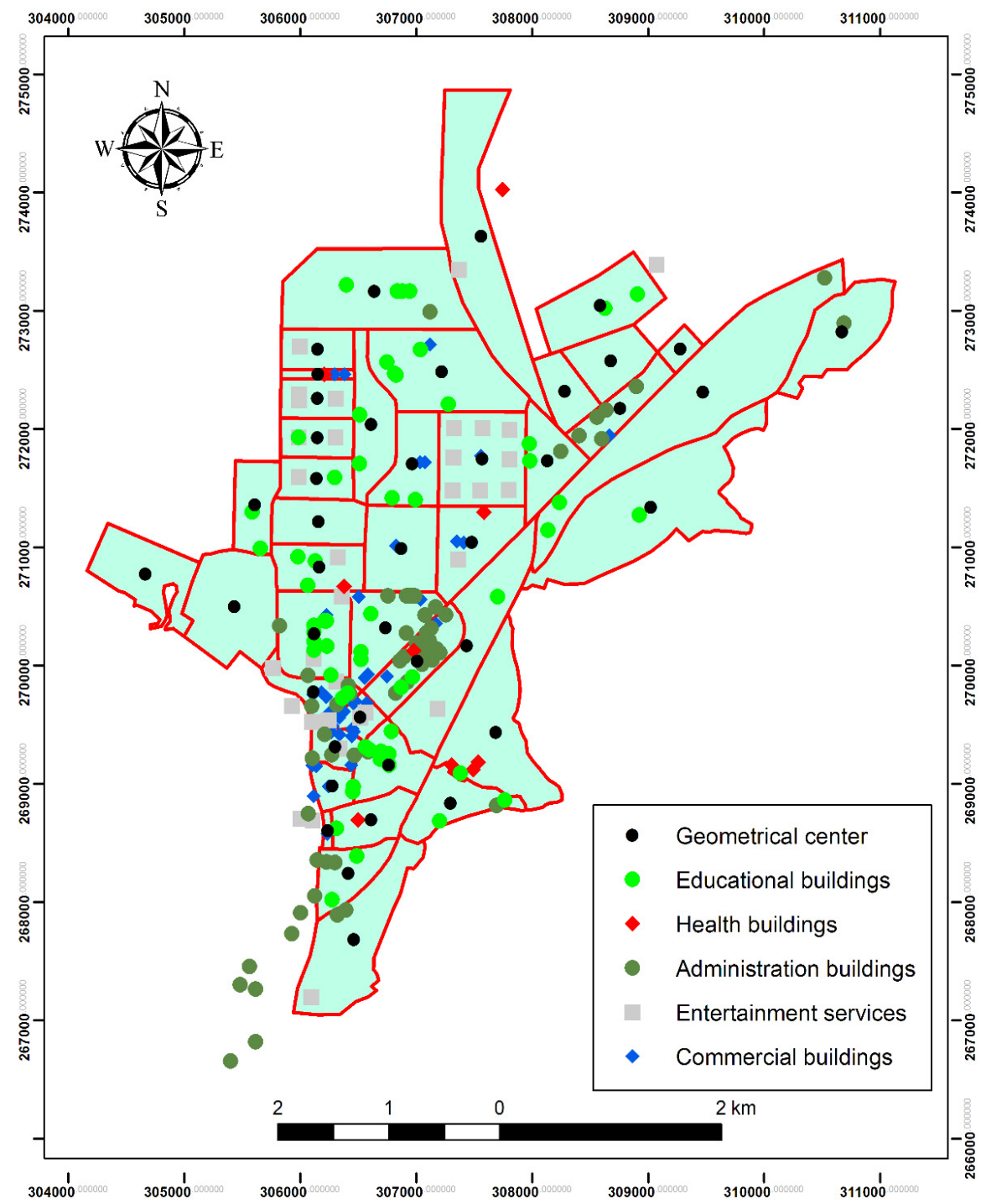

Figure 6. Calculating the Average Distance Between the Neighborhood Centre and a Specific Service Source: Preparation of researchers

Next, we calculated actual distances to the nearest service. Applying the distance method to the nearest service showed that educational services enjoyed the greatest ease of access. We examined the numerical ratio of the neighborhoods served within the three ranges, and the total average distances for the closest service were recorded at $389 \mathrm{~m}$, which is within the accepted standard of $400 \mathrm{~m}-500 \mathrm{~m}$. We can explain this by how these services are planned; they are subject to spatial criteria that locate them in most residential neighborhoods in the city, contributing to their ease of access. The convergence of educational services with administrative, commercial, and entertainment services reflects a homogeneous spatial distribution and did not exceed the accepted standard of 800 $\mathrm{m}$. Health services were close to the services above at the $1000 \mathrm{~m}$ range, which indicates an imbalance in their spatial distribution and a decrease in their number, as shown in Table (1). 
Table 1. The number of serviced neighborhoods and the average distances by the nearest service method

\begin{tabular}{|c|c|c|c|c|c|c|}
\hline & & \multicolumn{3}{|c|}{$\begin{array}{c}\text { Number of } \\
\text { neighborhoods served } \\
\text { within the distance }\end{array}$} & \multicolumn{2}{|c|}{ Distance to the nearest service (m) } \\
\hline & & 200 & م500 & 1000 & $\begin{array}{c}\text { Total } \\
\text { distance }(\mathrm{m})\end{array}$ & $\begin{array}{l}\text { Average distances } \\
\text { for all services }(\mathrm{m})\end{array}$ \\
\hline \multirow[t]{2}{*}{ Administrative } & 61 & 8 & 21 & 33 & 24236 & 577 \\
\hline & & $19 \%$ & $50 \%$ & $79 \%$ & & \\
\hline \multirow[t]{2}{*}{ Commercial } & 41 & 11 & 22 & 36 & 23253 & 554 \\
\hline & & $26 \%$ & $52 \%$ & $86 \%$ & & \\
\hline \multirow[t]{2}{*}{ Educational } & 58 & 16 & 30 & 39 & 16327 & 389 \\
\hline & & $38 \%$ & $71 \%$ & $93 \%$ & & \\
\hline \multirow[t]{2}{*}{ Health } & 9 & 3 & 17 & 29 & 35168 & 837 \\
\hline & & $7 \%$ & $40 \%$ & $69 \%$ & & \\
\hline \multirow[t]{2}{*}{ Entertainment } & 34 & 9 & 23 & 37 & 22076 & 526 \\
\hline & & $21 \%$ & $55 \%$ & $88 \%$ & & \\
\hline
\end{tabular}

Source: Preparation of researchers

The results of the second method, recording the number of services within a certain distance, were substantially close to the previous method. Educational services recorded the highest coverage rates for the three bands whereas health services recorded the lowest percentage. The results for commercial and administrative services remained close, and the number of services for the three domains were the same. See Table (2).

Table 2. the percentages of residential neighborhoods served by the number of services methods

\begin{tabular}{|c|c|c|c|c|c|c|c|c|c|c|c|c|c|c|c|}
\hline \multirow{3}{*}{$\begin{array}{l}\text { Number } \\
\text { of } \\
\text { services }\end{array}$} & \multicolumn{15}{|c|}{ The percentages of serviced residential neighborhoods within a radius of $(200,500,1000)(\mathrm{m})$} \\
\hline & \multicolumn{3}{|c|}{ Administrative } & \multicolumn{3}{|c|}{ Commercial } & \multicolumn{3}{|c|}{ Educational } & \multicolumn{3}{|c|}{ Health } & \multicolumn{3}{|c|}{ Entertainment } \\
\hline & 200 & 500 & 1000 & 200 & 500 & 1000 & 200 & 500 & 1000 & 200 & 500 & 1000 & 200 & 500 & 1000 \\
\hline 0 & $82 \%$ & $54 \%$ & $22 \%$ & $71 \%$ & $45 \%$ & $17 \%$ & $62 \%$ & $31 \%$ & $7 \%$ & $93 \%$ & $59 \%$ & $31 \%$ & $79 \%$ & $45 \%$ & $11 \%$ \\
\hline 1 & $12 \%$ & $7 \%$ & $7 \%$ & $14 \%$ & $14 \%$ & $14 \%$ & $29 \%$ & $7 \%$ & $0 \%$ & $7 \%$ & $36 \%$ & $40 \%$ & $14 \%$ & $12 \%$ & $17 \%$ \\
\hline 2 & $2 \%$ & $12 \%$ & $10 \%$ & $7 \%$ & $21 \%$ & $14 \%$ & $5 \%$ & $17 \%$ & $10 \%$ & $0 \%$ & $0 \%$ & $14 \%$ & $5 \%$ & $10 \%$ & $7 \%$ \\
\hline 3 & $2 \%$ & $2 \%$ & $10 \%$ & $2 \%$ & $2 \%$ & $7 \%$ & $0 \%$ & $14 \%$ & $5 \%$ & $0 \%$ & $5 \%$ & $10 \%$ & $2 \%$ & $12 \%$ & $5 \%$ \\
\hline 4 & $0 \%$ & $2 \%$ & $0 \%$ & $2 \%$ & $5 \%$ & $2 \%$ & $2 \%$ & $14 \%$ & $2 \%$ & $0 \%$ & 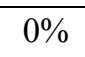 & 50 & $\bar{T}$ & $7 \%$ & $2 \%$ \\
\hline 5 & $0 \%$ & $5 \%$ & 370 & $0 \%$ & $2 \%$ & $10 \%$ & $0 \%$ & 270 & $3 \% 0$ & $0 \%$ & 070 & $7 \%$ & 070 & $2 \%$ & $5 \%$ \\
\hline 6 & $0 \%$ & $7 \%$ & $7 \%$ & $0 \%$ & $0 \%$ & $5 \%$ & $0 \%$ & $5 \%$ & $12 \%$ & $0 \%$ & $0 \%$ & $0 \%$ & $0 \%$ & $5 \%$ & $12 \%$ \\
\hline 7 & $0 \%$ & $0 \%$ & $0 \%$ & $0 \%$ & $0 \%$ & $2 \%$ & $2 \%$ & $0 \%$ & $7 \%$ & $0 \%$ & $0 \%$ & $0 \%$ & $0 \%$ & $2 \%$ & $10 \%$ \\
\hline 8 & $0 \%$ & $2 \%$ & $2 \%$ & $2 \%$ & $0 \%$ & $2 \%$ & $0 \%$ & $0 \%$ & $2 \%$ & $0 \%$ & $0 \%$ & $0 \%$ & $0 \%$ & $5 \%$ & $7 \%$ \\
\hline 9 & $0 \%$ & $2 \%$ & $2 \%$ & $0 \%$ & $2 \%$ & $2 \%$ & $0 \%$ & $5 \%$ & $7 \%$ & $0 \%$ & $0 \%$ & $0 \%$ & $\%$ & $\%$ & $5 \%$ \\
\hline 10 & $2 \%$ & $0 \%$ & $2 \%$ & $0 \%$ & $0 \%$ & $0 \%$ & $0 \%$ & $2 \%$ & $2 \%$ & $0 \%$ & $0 \%$ & $0 \%$ & $0 \%$ & $0 \%$ & $7 \%$ \\
\hline $10<$ & $0 \%$ & $7 \%$ & $33 \%$ & $0 \%$ & $7 \%$ & $24 \%$ & $0 \%$ & $2 \%$ & $40 \%$ & $0 \%$ & $0 \%$ & $0 \%$ & $0 \%$ & $\% 0$ & $12 \%$ \\
\hline
\end{tabular}

Source: Preparation of researchers 
Applying the average distance method for all services showed a slight difference in the results compared with the two previous methods. Here commercial services had the greatest ease of access, followed by educational and entertainment services, with a slight difference, while the health and administrative services were the most difficult to access. See Table (3).

Table 3. the number of serviced residential neighborhoods and the average distances for the average distance method for all services

\begin{tabular}{|c|c|c|c|c|c|c|c|}
\hline \multirow{3}{*}{$\begin{array}{l}\text { service } \\
\text { type }\end{array}$} & \multirow{3}{*}{$\begin{array}{l}\text { The total } \\
\text { number } \\
\text { of the } \\
\text { service }\end{array}$} & \multicolumn{6}{|c|}{ Distance rate method for all services( } \\
\hline & & \multicolumn{4}{|c|}{$\begin{array}{l}\text { Number of neighborhoods served within the } \\
\text { distance }\end{array}$} & \multicolumn{2}{|c|}{$\begin{array}{l}\text { Average distance for all services } \\
\text { (m) }\end{array}$} \\
\hline & & $2000 \mathrm{~m}$ & $3000 \mathrm{~m}$ & $4000 \mathrm{~m}$ & $5000 \mathrm{~m}$ & $\begin{array}{c}\text { Total } \\
\text { distance }(\mathrm{m})\end{array}$ & $\begin{array}{c}\text { Average distances } \\
\text { for all services } \\
(\mathrm{m})\end{array}$ \\
\hline \multirow{2}{*}{$\begin{array}{l}\text { Administra } \\
\text { e }\end{array}$} & 61 & 15 & 27 & 40 & 41 & 109332 & 2603 \\
\hline & & $35 \%$ & $64 \%$ & $95 \%$ & $98 \%$ & & \\
\hline \multirow[t]{2}{*}{ Commercis } & 41 & 20 & 32 & 41 & 41 & 94759 & 2256 \\
\hline & & $47 \%$ & $76 \%$ & $98 \%$ & $98 \%$ & & \\
\hline \multirow[t]{2}{*}{ Educationa } & 58 & 17 & 35 & 41 & 42 & 97829 & 2329 \\
\hline & & $40 \%$ & $83 \%$ & $98 \%$ & $100 \%$ & & \\
\hline \multirow[t]{2}{*}{ Health } & 9 & 13 & 34 & 41 & 42 & 103633 & 2467 \\
\hline & & $31 \%$ & $81 \%$ & $98 \%$ & $100 \%$ & & \\
\hline \multirow[t]{2}{*}{ Entertainm } & 34 & 18 & 36 & 41 & 42 & 98269 & 2340 \\
\hline & & $43 \%$ & $86 \%$ & $98 \%$ & $100 \%$ & & \\
\hline
\end{tabular}

Source: Preparation of researchers

We implemented a weighted distance analysis to measure ease of access to public services in the study area. The importance of this analysis lies in taking the variance in the population size of residential neighborhoods as a weighted factor in determining the degree of relative importance.

In our analysis, the distance equation was applied to the nearest service, and the distance equation was applied for all services. Using the actual distances and population numbers, we calculated the weighted distances for public services and from all residential neighborhoods. According to the average of these distances and the average rates for all services, weight of ease of access was calculated for each service. Using the formula for the number of services within a certain distance (or time) and in the same way as above, we calculated the weighted average number of services, as shown in Table (4). 
Table 4. The degree of ease of access to various services according to the method of measuring accessibility for public services

\begin{tabular}{ccccccc}
\hline services & \multicolumn{5}{c}{ The degree of accessibility } \\
\cline { 2 - 7 } & \multicolumn{2}{c}{ Method of nearest service } & Method of number of services & Average distances method \\
\cline { 2 - 7 } & $\begin{array}{c}\text { Distance } \\
\text { equation to } \\
\text { nearest } \\
\text { service } \\
(\mathrm{m})\end{array}$ & $\begin{array}{c}\text { Weighted } \\
\text { value }\end{array}$ & $\begin{array}{c}\text { Equation of } \\
\text { number of } \\
\text { services } \\
\text { (number) }\end{array}$ & $\begin{array}{c}\text { Weighted } \\
\text { value }\end{array}$ & $\begin{array}{c}\text { Distance } \\
\text { equation for } \\
\text { all services } \\
(\mathrm{m})\end{array}$ & $\begin{array}{c}\text { Weighted } \\
\text { value }\end{array}$ \\
\hline Commercial & 435 & 1.08 & 1.48 & 1.28 & 1968 & 1.09 \\
\hline Educational & 301 & 1.56 & 3.24 & 0.59 & 2064 & 1.04 \\
\hline Administrative & 690 & 0.68 & 1.63 & 1.17 & 2381 & 0.90 \\
\hline Health & 509 & 0,92 & 0.83 & 2.29 & 2208 & 0.97 \\
\hline Entertainment & 414 & 1.13 & 2.32 & 0.82 & 2072 & 1.03 \\
\hline Total & 469.8 & 1.08 & 2 & 1.23 & 2138.6 & 1 \\
\hline
\end{tabular}

Source: Preparation of researchers

Table (4) shows contrasts among the three equations. The equation for the distance to the nearest service shows that educational services are the most accessible, followed by entertainment, commercial, health, and, finally, administrative. The equation for the number of services within a certain distance (or time) shows that educational services are the most accessible, followed by entertainment, administrative, commercial, and, finally, health. The distance equation for all services shows that administrative services are the most accessible, followed by educational, health, entertainment, and, finally, commercial services.

\section{Conclusion}

The results of this research reflect the possibility of measuring the accessibility of public services in the city of Aqaba using available spatial analysis tools within the GIS software environment. Some suitable suggestions have been developed to solve the problems in the study area.

The results of the spatial analysis of public services using the distance method to the nearest service showed that educational services recorded the highest ease of access by the numerical ratio of the neighborhoods served and within the three ranges. The total average distances of the nearest service were recorded $(389 \mathrm{~m})$, which is within the accepted standard of $400 \mathrm{~m}-500 \mathrm{~m}$. There is a convergence with administrative, commercial and entertainment services, which reflects a homogeneous spatial distribution and does not exceed the accepted standard of $800 \mathrm{~m}$. Health services approached the range of $1000 \mathrm{~m}$. The results of the spatial analysis using the method of number of services within a certain distance showed that educational services had the highest coverage rates for the three ranges $(200 \mathrm{~m}, 500 \mathrm{~m}, 1000 \mathrm{~m})$, whereas health services recorded the lowest and commercial and administrative services remained convergent.

Applying the average distance method for all services showed that there is a slight difference in the results from the two methods (distance to the nearest service, number of services); they showed that commercial services have the highest accessibility, followed by educational and entertainment services, with a slight difference, whereas health and administrative services are less easily accessed.

We applied the method of weighted distances using the three equations. The distance to the nearest service equation showed that educational services are the most accessible, followed by recreational, commercial, health, and finally administrative. The equation for the number of services within a certain distance (or time) showed that educational services are the most accessible, followed by entertainment, administrative, commercial, and, finally, health services. The equation for the distances of all services showed that administrative services are most accessible, followed by educational, health, recreational, and, finally, commercial services. 


\section{Recommendations}

Our recommendations, based on the analysis and discussion of the results, are that the population increase in underserved or partially served areas (especially the peripheral neighborhoods) should be considered so that the people who live there are provided with public services within an appropriate distance that covers the scope of the impact of these services. We also believe it is necessary to adopt ease of access to public services as a major factor when distributing and planning the sites of these services in the city while also acknowledging the presence of other factors. It is important to develop planning standards for public services that are commensurate with the current reality of Jordanian cities but also to ensure a certain level of conformity to international standards for the study area before adopting and applying them. The results of this study can be used to determine such standards. In addition, our results point to the necessity of providing some public services such as health care centres in neighborhoods that are not served or that face difficulty in accessing these services, such as the northern neighborhoods of the city. This study contributes to a greater understanding of spatial analysis for accessibility to public services using GIS in the decision-making process.

\section{References}

Abdullah, M. (1981). History of City Planning, (1rd Edition) The Anglo-Egyptian Library. Wahdan Publishing House, Cairo, Egypt.

Albacete, X., Olaru, D., Paül. V., Biermann, S. (2017). Measuring the Accessibility of Public Transport: A Critical Comparison Between Methods in Helsinki. Applied Spatial Analysis and Policy, (9), 161-188. https://doi.org/10.1007/s12061-015-9177-8

Apparicio, P., Abdelmajid, M., Riva. M., Shearmur, R. (2008). Comparing alternative approaches to measuring the geographical accessibility of urban health services: Distance types and aggregation-error issues. International Journal of Health Geographic, 7(7), 1-14.https://doi.org/10.1186/1476-072X-7-7

Al-Sahili, K., Aboul-Ela., M. (1992). Accessibility of Public Services as an Indicator of Transportation System Sustainability: the Case of Irbid, Jordan. Journal of Urban Planning \& Development, 118(1), 1-12.

https://doi.org/10.1061/(ASCE)0733-9488(1992)118:1(1)

Aqaba Special Economic Zone Authority. (2015). A map of land use in the city of Aqaba. Aqaba, Jordan.

Awada, G. (2007). Measures of Accessibility to Public Services in Palestinian Cities, "Case Study, Nablus City, (Unpublished master's thesis). An-Najah National University, Nablus, Palestine.

Chapin, F., Edward, J., David, J. (2006). Urban Land use Planning, (5rd Edition). University of Illinois, Press Urbana, p164.

Department of Statistics. (2004). Population and housing census for Aqaba city, Amman, Jordan.

Department of Statistics. (2007). Population and housing census for Aqaba city, Amman, Jordan.

Department of Statistics. (2015). Aqaba City Population and Housing Census, Amman, Jordan.

Gutierrez. J., Monzon, A., Pinero, J. (1998). Accessibility, network efficiency, and transport infrastructure planning. Environment and Planning, 30(8), 1337 -1350.https://doi.org/10.1068/a301337

Handy,.L., Niemeier,.A. (1997). Measuring Accessibility: An Exploration of Issues and Alternatives. Environment and Planning, (29), 1175-94. https://doi.org/10.1068/a291175

JaePark.,S. (2012). Measuring public library accessibility: A case study using GIS. Library \& Information Science Research, 34(1) 13-21 https://doi.org/10.1016/j.lisr.2011.07.007

Karst, T., Geurs, A., Bert V. (2004). Accessibility evaluation of land- use and transport strategies: review and research directions. journal of Transport Geography, (12), 127-140. https://doi.org/10.1016/j.jtrangeo.2003.10.005

Neutens,T., Schwanen,T., Witlox, F., Maeyer., P. (2010). Evaluating the Temporal Organization of Public Service Provision Using Space-Time Accessibility Analysis. Urban Geography, 31(8), 1039-1064. https://doi.org/10.2747/0272-3638.31.8.1039

Nicholls,S. (2010). Measuring the accessibility and equity of public parks: a case study using GIS. Managing Leisure, 6(4), 201-219.https://doi.org/10.1080/13606710110084651 
Polo, G., Acosta, C., Ferreira, F., Dias, R. (2015). Location-Allocation and Accessibility Models for Improving the Spatial Planning of Public Health Services. PLoS ONE, 10(3), 1-14. https://doi.org/10.1371/journal.pone.0119190

Shalaby., A. (2005). The Use of Geographic Information Systems in Selecting the Most Suitable Sites for Governmental Hospitals in Al-Montazah District - Alexandria Governorate. Journal of the Faculty of Arts Alexandria University, (54), 3-38.

Tindall., D. (2005). Local Transportation Plan Accessibility Study. Modelling Report, Northumberland County Council, MVA Project.

\section{Copyrights}

Copyright for this article is retained by the author(s), with first publication rights granted to the journal.

This is an open-access article distributed under the terms and conditions of the Creative Commons Attribution license (http://creativecommons.org/licenses/by/4.0/). 